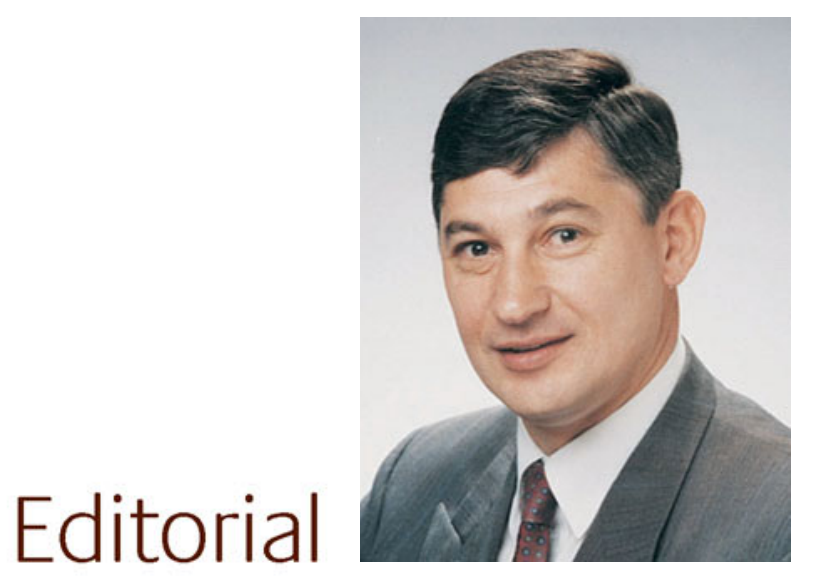

\section{Significant Inventions}

I was recently interviewed in the street for a radio programme. I was asked what I thought was the most significant scientific invention since World War II. My answer was the transistor because of what it has enabled us to do in electronics and communications and the impact these have had on our lives. Do you agree or do you have a different opinion? We might ask you the question, "What is the most significant invention based on gold?" What would it be, I wonder.

As a journal editor looking back on 10 years of editing Gold Bulletin, it is amazing how much easier the mechanics of it has become, thanks to the advances in IT and computing. We no longer receive manuscripts hand-typed or even hand-written, which needs re-typing, and real photographs and diagrams drawn out on paper, which we carefully collect and send off to the publisher. We do not rely on the mail or fax for communicating with authors and referees, with the associated time delay this puts into the schedule. We do it all by e-mail with all the manuscripts and figures attached as files. And we collect all the materials on CD and send it to our publisher, or even e-mail it to him. It's simply amazing!

\section{Top 10 Articles in Gold Bulletin}

This electronic wizardry now allows us to publish Gold Bulletin as an E-journal on its own dedicated website, which the reader can browse and download for free. And browse the archive for previously published articles too. As you will see in this issue, we publish the 'top 10' most popular articles that have been downloaded from our website in the months of April and March. Any surprises? Yes, do I hear you say? For example, the Bond \& Thompson paper on the mechanism of gold catalysis is now several years old but remains of high interest. Perhaps not so surprising when one considers the current strong interest in this scientific field. Our surprise has been the sheer volume of back articles that has been accessed. Clearly, the papers and other information we publish are of interest to our readership. We shall publish such figures from time to time in future issues.

We are proud of the fact that Gold Bulletin is held in high regard in the scientific community, as judged by its good rating in the Citation Index. The aim is to maintain this position and another way of judging that is the number of times readers access and download articles. It will help us to ensure we publish in areas of interest to you. In this regard, we do welcome feedback from you. Is the website easy to use? Are there scientific areas you would like to see more articles on? What other features do you want? Is Gold in the News of interest? Do let us know. E-mail me on editor@goldbulletin.org.

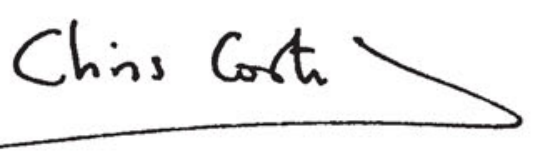

Christopher W. Corti

Editor 